\title{
El asilo político concedido a nacionales ecuatorianos en México
}

\section{Ingrid Berlanga Vasile*}

En México, "es una facultad discrecional del Estado admitir a un extranjero en su territorio y actuar como su protector, al considerar que el individuo, debido a su perfil público, es objeto de persecución política". ${ }^{1}$ La concesión del asilo diplomático es un acto de política exterior, por lo que corresponde a la Secretaría de Relaciones Exteriores su concesión, en conjunto con la Secretaría de Gobernación, previa consideración de la Representación de México en el Exterior, permitir motivar la protección solicitada por la persona en territorio del Estado asilante.

En octubre de 2019 Ecuador atravesaba por una crisis socioeconómica y política en cuyo contexto se aprobaron medidas económicas que conllevaron al incremento de los precios de combustibles subvencionados por el gobierno, entre 130\% en el diesel y 30\% en la gasolina extra. Tal decisión generó profundo malestar en la sociedad, en particular en el sector trabajador de menores recursos, pueblos indígenas, estudiantes universitarios, agricultores, sindicalistas y transportistas, quienes protagonizaron protestas que paralizaron al país por 13 días, llegando incluso a la violencia y al vandalismo. El presidente Lenín Moreno declaró estado de excepción en todo el territorio ecuatoriano.

* Fletcher School, Estados Unidos de América; ORCID ID: https: / / orcid.org/0000-00032290-8995,ingridbervas@gmail.com. Las opiniones plasmadas en el texto no corresponden, necesariamente en su totalidad, a la posición del gobierno mexicano.

1 Lineamientos para atender solicitudes de asilo, Secretaría de Relaciones Exteriores de México, 2016, disponible en: https://extranet.sre.gob.mx/images/stories/asilo/asilo2016.pdf. 
La Secretaría de Relaciones Exteriores publicó un comunicado expresando la preocupación del gobierno de México por los sucesos e hizo un llamado a respetar el Estado de derecho y los derechos humanos en Ecuador. ${ }^{2} \mathrm{~A}$ raíz de estos disturbios, la Comisión Interamericana de Derechos Humanos (CIDH) realizó una visita a Ecuador en octubre de 2019, y confirmó que las medidas económicas implementadas por el gobierno no fueron antecedidas por un proceso de consulta ciudadana ni de una evaluación de su impacto. El 13 de octubre de ese año se llegó a un acuerdo entre el gobierno y los dirigentes de las organizaciones opositoras, derogándose las medidas.

La organización política ecuatoriana "Revolución Ciudadana" — simpatizante del expresidente Rafael Correa - es un actor decididamente opuesto a los intereses e ideología del partido del gobierno "Alianza País". El gobierno le atribuyó la responsabilidad de las protestas y la autoría de los hechos violentos ${ }^{3}$ y acusó a varios de sus miembros de instigación, terrorismo y sabotaje. Siete activistas políticos y asambleístas de nacionalidad ecuatoriana solicitaron asilo político en la Embajada de México en Ecuador como resultado de la persecución política que habían sufrido desde meses atrás. Gabriela Rivadeneira, quien aseguró que fue vetada por el gobierno ecuatoriano para contender para las elecciones de 2021, y que había sido blanco de amenazas, persecuciones y difamaciones, fue la primera en solicitar el resguardo de la Embajada de México. Dos días después presentaron su solicitud los asambleístas Soledad Buendía y Carlos Viteri, lo mismo que el abogado alterno Luis Fernando Molina y los cónyuges de Gabriela Rivadeneira (Luis Flores), de Soledad Buendía (Edwin Jarrín) y de Carlos Viteri (Tania Pauker). ${ }^{4}$ Todos afirmaban haber sido víctimas de la "desinstitucio-

2 Comunicado No. 353 de la Secretaría de Relaciones Exteriores, "México expresa su preocupación por los graves sucesos en Ecuador", 9 de octubre de 2019, disponible en: https: / / www.gob. mx /sre/prensa / mexico-expresa-su-preocupacion-por-los-graves-sucesos-que-ocurrenen-ecuador.

3 La Comisión Interamericana de Derechos Humanos acusó de "situaciones de violencia y represión alarmantes” a las registradas durante las protestas en Ecuador — que iniciaron el 3 de octubre - por las medidas de austeridad económica adoptadas por el gobierno de Lenin Moreno, que incluían la eliminación del subsidio a los combustibles.

4 "Qué derechos otorga México a los asambleístas asilados de Ecuador", El Universo, 11 de enero de 2020, disponible en: https://www.eluniverso.com/noticias/2020/01/10/nota / 7684827 /asilo-diplomatico-asambleistas-mexico-ecuador; "México otorga asilo político a asambleístas ecuatorianos, Carolina Rivera”, Milenio, 9 de enero de 2020, disponible en: https: / / www.milenio.com/politica/mexico-dara-asilo-politico-asambleistas-ecuador. 
nalización" del Estado y de la judicialización de la política, así como de la falta de reconocimiento del derecho de los partidos políticos a la oposición. Habían sido amenazados y perseguidos. Ninguno tenía un proceso judicial en su contra ni había evidencia que probara que, efectivamente, eran culpables de lo que se les acusaba.

El 16 de octubre de 2019 un grupo de unos 100 ecuatorianos denominados "Ciudadanos por la Patria" llevó a cabo una protesta pacífica frente a la Embajada de México en Quito para exigir que las personas ecuatorianas que ingresaron a la Embajada no recibieran el asilo político del gobierno mexicano. ${ }^{5}$ Entre gritos de "cárcel para terroristas, corruptos y golpistas", un representante de la embajada de México en Ecuador solicitó a los manifestantes que presentaran por escrito sus planteamientos y éstos fueron transmitidos a las instancias mexicanas competentes.

Es importante señalar que no existe un procedimiento universal para la concesión del asilo. El procedimiento se ha derivado de la práctica regional y los aspectos generales contenidos en los instrumentos convencionales regionales. Los instrumentos invocados por parte de las siete personas ecuatorianas para solicitar el asilo político a México fueron, en primera instancia, la Convención sobre Asilo (La Habana, 1928); el artículo 14 de la Declaración Universal de los Derechos Humanos (1948), que señala que "en caso de persecución, toda persona tiene derecho a buscar asilo, y a disfrutar de él en cualquier país. Este derecho no podrá ser invocado contra una acción judicial realmente originada por delitos comunes o por actos opuestos a los propósitos y principios de las Naciones Unidas”. Asimismo, el artículo 27 de la Declaración Americana de los Derechos y Deberes del Hombre: "Toda persona tiene el derecho de buscar y recibir asilo en territorio extranjero, en caso de persecución que no sea motivada por delitos de derecho común y de acuerdo con la legislación de cada país y con los convenios internacionales". El artículo 5o. de la Convención sobre Asilo Diplomático y Convención sobre Asilo Territorial de 1954 aclara que "el asilo no podrá ser concedido sino en casos de urgencia y por el tiempo estrictamente indispensable para que el asilado salga del país con las seguridades otorgadas por el gobierno del Estado territorial a fin de que no peligre

5 "Protestan en Embajada de México por asilo a «golpistas» en Ecuador", El Sol de México, 16 de octubre de 2019, disponible en: https: / /www.elsoldemexico.com.mx/mundo/protestan-enembajada-de-mexico-por-asilo-a-golpistas-en-ecuador-4326740.html. 
su vida, su libertad o su integridad personal, o para que se ponga de otra manera en seguridad al asilado". De igual modo, indica que corresponde al Estado que otorga el asilo la calificación y el otorgamiento del mismo, y que ningún Estado está obligado a entregar a otro o a expulsar de su territorio a personas perseguidas por motivos políticos.

El país que concede el asilo, en este caso México, se responsabiliza en las consecuencias de la decisión de conceder el asilo, que implica mantenerlos en un estado de dignidad humana. Durante el tiempo que las siete personas permanecieron resguardadas en la Embajada de México se les proporcionó alimento, protección y lo estrictamente necesario, permitiéndoles visitas de sus familiares y amigos, y, ante todo, resguardando su integridad física.

Otras normativas a las que aludieron los asilados fueron la Convención sobre Asilo Territorial (1967): “Todo Estado tiene derecho, en ejercicio de su soberanía, a admitir dentro de su territorio a las personas que juzgue conveniente, sin que por el ejercicio de este derecho ningún otro Estado pueda hacer reclamo alguno. Le corresponde al Estado que otorga el asilo la calificación y el otorgamiento del mismo".

A su vez, el artículo 22 de la Convención Americana sobre Derechos Humanos (Pacto de San José) de 1969 se refiere al derecho de circulación y de residencia: "Toda persona tiene el derecho de buscar y recibir asilo en territorio extranjero en caso de persecución por delitos políticos o comunes conexos con los políticos y de acuerdo con la legislación de cada Estado o los Convenios Internacionales".

Finalmente, el artículo 6o. de la Convención sobre el Asilo y Refugio Político de Montevideo (1939): "el agente diplomático que concedió el asilo podrá exigir las garantías necesarias para que el refugiado salga del país respetándose la inviolabilidad de su persona”.

En México, la reforma constitucional en materia de derechos humanos promulgada el 10 de junio de 2011 incorporó, en el artículo 11, un segundo párrafo que dispone: "En caso de persecución, por motivos de orden político, toda persona tiene derecho de solicitar asilo; por causas de carácter humanitario se recibirá refugio. La ley regulará sus procedencias y excepciones". ${ }^{6}$ La legislación aplicable al asilo en México incluye la Ley de Migración, la

6 Lineamientos para atender solicitudes de asilo y refugio, Secretaría de Relaciones Exteriores de México, 2016, disponibles en: https://extranet.sre.gob.mx/images/stories/asilo/asi 1o2016.pdf. 
Ley del Servicio Exterior Mexicano y la Ley sobre Refugiados, Protección Complementaria y Asilo Político de México. La Secretaría de Relaciones Exteriores y la Secretaría de Gobernación se encargan, de manera conjunta, de atender y dar seguimiento a los casos de asilos y refugios. ${ }^{7}$

Según la Ley de sobre Refugiados, Protección Complementaria y Asilo Político de México, el artículo 61 señala que podrá solicitar asilo político "todo extranjero que encuentre en peligro su vida, su libertad o seguridad por ideas o actividades políticas directamente relacionadas con su perfil público, y carezca de la protección de su país”. Mientras que el artículo 54 señala que "la Secretaría de Relaciones Exteriores adoptará las medidas necesarias para brindar asistencia institucional y auxiliar a los refugiados para facilitar su integración en el país". Y el artículo 55 indica que esta cartera de Estado

...podrá establecer convenios de coordinación con dependencias y entidades federales y locales, para que los solicitantes que se encuentren en estado de particular vulnerabilidad puedan recibir apoyos para atender sus necesidades inmediatas. Asimismo, podrá establecer mecanismos de colaboración con organizaciones de la sociedad civil y todas aquellas instituciones que puedan otorgar atención directa a solicitantes y refugiados.

El canciller mexicano, Marcelo Ebrard, y su homólogo ecuatoriano se reunieron en la Ciudad de México previo a la ceremonia por el inicio de la

7 A la Secretaría de Relaciones Exteriores le corresponde orientar a los solicitantes de asilo y asilados sobre sus derechos y obligaciones, llevar un registro actualizado de los solicitantes de asilo y asilados y resolver sobre el retiro y la renuncia de asilo. Por su parte, a la Secretaría de Gobernación le compete, de manera conjunta con la Secretaría de Relaciones Exteriores, promover y coordinar acciones públicas, estrategias y programas orientados a la protección y asistencia de asilados; promover soluciones a la problemática que enfrentan los asilados durante su estancia en territorio nacional; formular, coordinar, dar seguimiento, evaluar y difundir criterios y programas encaminados a la atención de asilados; establecer las bases y los procedimientos de coordinación entre las dependencias y entidades de los tres órdenes de gobierno, que participen en la atención a asilados; atender a los asilados con pleno respeto a sus derechos humanos; adoptar las medidas a su alcance para que los asilados no sean objeto de discriminación motivada por origen étnico o nacional, género, edad, discapacidad, condición social o económica, o cualquiera otra que tenga por objeto impedir o anular el reconocimiento o el ejercicio de sus derechos, y adoptar todas las medidas necesarias para brindar asistencia institucional a los asilados. 
presidencia pro tempore de México en la Comunidad de Estados Latinoamericanos y Caribeños (CELA). La reunión trató los aspectos más importantes de la relación bilateral, de acuerdo con un tuit de la Embajada ecuatoriana en México que no reveló más detalles.

Cabe hacer mención, brevemente, de la simultaneidad de los hechos que, en diciembre de 2019, el gobierno mexicano denunció: el asedio de su Embajada en Bolivia para que entregara a la justicia boliviana a nueve ex funcionarios cercanos al ex presidente Evo Morales, resguardados en la Embajada. Además, la embajadora Teresa Mercado fue declarada persona non grata y tuvo que abandonar Bolivia. En el caso de Ecuador la historia fue distinta y la relación bilateral no fue afectada a nivel político, probablemente debido a las negociaciones que estaban teniendo lugar para elTratado de Libre Comercio México-Ecuador y al apoyo que México ha brindado a Ecuador para convertirse en miembro de pleno derecho de la Alianza del Pacífico. Aparte de que “entre 2000 y 2018, México fue el país que más inversión extranjera inyectó en Ecuador con más de 1,550 millones de dólares”.

Aproximadamente un mes después de que los siete ecuatorianos ingresaron a la Embajada de México, se obtuvo la autorización por parte del gobierno mexicano para su ingreso a territorio nacional con el estatus de personas asiladas políticas. Citando el artículo 12 de la Convención sobre Asilo Diplomático, una vez que se otorga el asilo "el Estado asilante puede pedir la salida del asilado para territorio extranjero, y el Estado territorial está obligado a dar inmediatamente, salvo caso de fuerza mayor, las garantías necesarias [...] y el correspondiente salvoconducto”. Además enfatiza que "la situación jurídica de la persona asilada no puede quedar en el limbo o prolongarse indefinidamente", por lo que se obliga en la Convención Americana de Derechos Humanos "la salida de los asilados hacia territorio extranjero, en el entendido de que la protección es por un tiempo estrictamente indispensable". ${ }^{8}$ No obstante lo anterior, el gobierno ecuatoriano demoró casi dos meses en otorgar las facilidades de salida del país de las siete personas asiladas y sus respectivos hijos menores de edad. La CIDH tuvo conocimiento de la protección y resguardo que el gobierno de México otorgó a los ecuatorianos y recomendó a Ecuador entregar los respectivos salvoconductos para que así pudieran

8 Opinión consultiva de la Corte Interamericana de Derechos Humanos, OC25-18. 
Esta revista forma parte del acervo de la Biblioteca Jurídica Virtual del Instituto de Investigaciones Jurídicas de la UNAM

ejercer su derecho humano a obtener asilo y refugio y se preservaran sus respectivos núcleos familiares. ${ }^{9}$

El 9 de enero de 2019, 86 días después de haber ingresado a la Embajada, finalmente volaron a México en un vuelo comercial las personas ecuatorianas, junto con sus cónyuges e hijos menores de edad, con apoyo del personal de la Embajada de México. ${ }^{10}$ La Secretaría de Relaciones Exteriores de México publicó un comunicado señalando:

...en apego a la tradicional diplomacia y política de protección internacional, concedió asilo político a siete nacionales ecuatorianos [...] El Gobierno de México reconoce el respeto y la observancia (cumplimiento) al derecho internacional en materia de asilo que ha dado el Estado del Ecuador y agradece la institucionalidad de las autoridades de ese país durante todo el proceso. Asimismo, México reitera su compromiso con el respeto, la protección y la promoción de los derechos humanos de todas las personas, independientemente de su afinidad política. Finalmente, México aprovecha la oportunidad para destacar el excelente estado de las relaciones con el gobierno y el pueblo ecuatoriano, lo que redunda en beneficio de ambas naciones hermanas. ${ }^{11}$

El entonces canciller ecuatoriano, José Valencia, justificó la salida del país de los asambleístas y sus familiares

...como muestra de respeto del marco jurídico internacional, evitando alimentar la narrativa de la persecución política a la que habitualmente se aferran los funcionarios o altos cargos del Gobierno anterior que enfrentan a la justicia, ya sea por las protestas de octubre o por casos de corrupción [...] El Gobierno está seguro

9 "Vence el plazo para que el Estado informe a la CIDH sobre situación de correístas en la embajada de México", El Universo, 7 de enero de 2020, disponible en: https: / / www.eluniver so.com/noticias / 2020/01/07/nota / 7679637/cidh-asambleistas-correistas-embajada-mexico-ga briela-rivadeneira; comunicado de prensa de la $\mathrm{CIDH}$, "CIDH presenta observaciones de su visita a Ecuador”, 14 de enero de 2020, disponible en: https://www.oas.org/es/cidh/prensa/ comunicados/2020/008.asp.

10 Camhaji, Elías, "México da asilo a cuatro opositores ecuatorianos", El País, 9 de enero de 2020, disponible en: https://elpais.com/internacional/2020/01/09/america/157859 1378_177456.html.

11 Comunicado de la Secretaría de Relaciones Exteriores No. 14, "Nacionales ecuatorianos asilados viajan a México", 9 de enero de 2020, disponible en: https: / /www.gob.mx/sre/prensa/ nacionales-ecuatorianos-asilados-viajan-a-mexico. 
de que la conspiración para atentar contra la democracia y los hechos violentos de octubre serán esclarecidos por la justicia y que sus responsables serán sancionados siguiendo el debido proceso. Al mismo tiempo, siguiendo la línea de respeto a los instrumentos internacionales que han mantenido el Gobierno del presidente Lenín Moreno, esta semana comunicó a la Embajada de México que se brindarían las facilidades necesarias para que estos ciudadanos salgan del Ecuador [...] Esto evidencia una vez más, como reconoce la ciudadanía y la comunidad internacional, que detrás del discurso de persecución política está un interés político de un sector que busca la impunidad ante los delitos por los que muchos son hoy procesados por órganos judiciales independientes. Hoy Ecuador regresó al orden democrático y respeta plenamente el ordenamiento jurídico nacional y sus responsabilidades derivadas del derecho internacional... ${ }^{12}$

Cabe señalar que una veintena de militantes correístas, que ocuparon altos cargos en ese gobierno, han salido de Ecuador en los últimos tres años, la mayoría tras haber sido procesados o investigados en casos de corrupción o por irregularidades en la administración pública; 10 de ellos se han asilado en México. ${ }^{13}$

El otorgamiento del asilo diplomático a los siete ecuatorianos y sus hijos por parte de México fue un acto pacífico y humanitario, y como tal, conforme a la Declaración sobre el Asilo Territorial, no puede ser considerado inamistoso por el Estado ecuatoriano. México hizo uso de su absoluta libertad para otorgar asilo y admitir en "su territorio a las personas que juzgue conveniente, sin que por el ejercicio de este derecho ningún otro Estado pueda hacer reclamo alguno", igualmente, conforme a la Convención sobre Asilo Territorial. Asimismo, el asilo no fue sugerido o estimulado; se otorgó con independencia del hecho de que se tratara de opositores al régimen de

12 Video con el mensaje del canciller ecuatoriano, José Valencia, en "Gabriela Rivadeneira y asambleístas correístas salen a México tras refugiarse más de 86 días en Embajada en Quito”, El Comercio, 9 de enero de 2020, disponible en: https://www.elcomercio.com/actualidad/asam bleistas-correistas-embajada-viaje-mexico.html.

13 Además de los siete que se refieren en el presente artículo, se encuentran el ex canciller Ricardo Patiño, el ex secretario de Senecyt, René Ramírez, y Carlos Ochoa, ex superintendente de Comunicación. En Estados Unidos se encuentran asilados Rommy Vallejo, ex secretario de Inteligencia; Pedro Delgado, ex presidente del Banco Central, y el ex contralor, Carlos Pólit. En Perú se encuentra el ex ministro Ramiro González, y hay cinco ex funcionarios de gobierno cuya confirmación de lugar de residencia no se ha confirmado. 
Esta revista forma parte del acervo de la Biblioteca Jurídica Virtual del Instituto de Investigaciones Jurídicas de la UNAM

Lenín Moreno, por lo que no constituyó una intervención en los asuntos internos de otros Estados. La posición del gobierno mexicano fue haber procedido por razones humanitarias y de acuerdo con el derecho internacional, su marco jurídico interno y en congruencia con su tradición diplomática de apoyo y protección a los perseguidos políticos en el mundo. 